\title{
Chemical compatibility of interim material and bonding agent on shear bond strength
}

\author{
Jonghyuk Lee* \\ Department of Prosthodontics, College of Dentistry, Dankook University, Cheonan, Republic of Korea
}

Purpose: The purpose of this study is finding proper bonding agents to be used when adding bis-acryl composite provisional materials. Materials and Methods: Three bonding agents with different chemical compositions were included in this study. Forty disk shaped specimens of bis-acryl composite provisional material were prepared and divided into 4 groups according to the bonding agents. Control group didn't have bonding agent. Through the Teflon mould with $4.0 \mathrm{~mm}$ diameter hole with $4.0 \mathrm{~mm}$ thickness the same bis-acryl composite provisional material was added on the disks after the surface of each specimen was treated with designated bonding agent according to the manufacturer's instructions. Shear bond test was performed and the fractured surfaces were inspected with a microscope. One-way analysis of variance was conducted and the result was further analysed with Turkey post hoc test at the significance level of 0.05 . Results: The highest strength was acquired from the specimens bonded with chemical cure system and it was statistically significant $(P<0.05)$. This group showed $100 \%$ cohesive failures. The lowest bonding strength was recorded from the specimens used conventional light cure bonding agent, and this group's result was similar with the control group. The group used a light cure bonding agent claiming improved compatibility revealed significantly higher bond strength to the traditional light cure bonding agent group in a statistically significant way $(P=0.043)$. Conclusion: According to the bonding agent used the shear bond strength was significantly affected. Therefore the choice of proper bonding agent is important when hiring a bonding agent to add bis-acryl composite provisional materials. (J Dent Rehabil Appl Sci 2016;32(4):293-300)

Key words: bis-acryl composite provisional material; provisional restoration; shear bond strength; bonding agent

\begin{abstract}
서론
임시수복물은 보철치료 과정에서 치아를 보호해 줄 뿐 아니라 저작기능 및 심미성을 회복시켜 주어 환자가 치 료기간 동안 느끼는 불편을 최소로 해주어야 한다. ${ }^{1-3}$ 또 한 파절된 부분의 수리나 변연의 적합성 향상, 교합의 양 상이나 심미성 개선을 위해 치아의 형태를 변경이 필요 한 경우 쉽게 첨가나 삭제 과정을 통해 형태의 변경이 가 능해야 한다. ${ }^{2-8}$ 비스아크릴 임시수복 재료는 중합반응 시 수축과 발열이 작고 높은 강도와 변연적합도를 가져

*Correspondence to: Jonghyuk Lee

Associate Professor, Department of Prosthodontics, College of Dentistry, Dankook University, 119, Dandae-ro, Dongnam-gu, Cheonan, 31116, Republic of Korea Tel: +82-41-550-0253, E-mail: hyuk928@dankook.ac.kr

Received: November 28, 2016/Last Revision: December 13, 2016/Accepted:

December 19, 2016
\end{abstract}

최근 임시수복물 재료로 그 활용이 늘고 있다. ${ }^{3,6-11}$ 그러 나 이러한 장점에도 불구하고 비스아크릴 임시수복 재료 는 같은 재료의 추가에 의한 수정 시 약한 수리강도를 가 지기 때문에 ${ }^{3,4,12}$ 사용하던 보철물이 파절되거나 형태를 많이 변경해야 하는 경우는 재제작이 권유되기도 하였 다. ${ }^{12,13}$

비스아크릴 임시수복 재료로 만들어진 임시보철물에 작은 결함이 있거나 수정이 필요한 경우는 flowable 레진 을 이용하여 수정이 가능하며,8 수리 강도에 있어서도 유 용한 결과를 보였다..$^{7,14,15}$ 그러나 flowable 레진을 이용

Copyright C 2016 The Korean Academy of Stomatognathic Function and Occlusion. (c) It is identical to Creative Commons Non-Commercial License. 
한 방법은 그 적용에 한계가 있고 대부분의 비스아크릴 임시수복 재료를 사용한 임시보철물이 직접법으로 만들 어 지는 이면에는 재료의 첨가나 수리가 어렵다는 단점 이 큰 이유로 작용한다. 복합 레진의 수리에서 재료간의 결합을 향상시키기 위해 다양한 표면 처리가 사용되는 데, 표면의 거칠기를 증가시키고 화학적인 결합을 증가시 키기 위해 연마처리, 입자분사 마모, 산부식 방법들이 비 교되었고 특수한 프라이머나 silane 처리 등의 화학적 성 분을 본딩제와 함께 도포해 보기도 하였다. ${ }^{16-26}$ 최근 본딩 제의 경항은 시술의 단계를 간소화 하고 좀더 많은 재료 에 호환성을 가지기 위해 다양한 재료를 첨가하고 selfetching이 가능하도록 진화하고 있다..$^{19,20,22,23}$ 그러나 재 료의 중합 방식은 접촉하는 물질의 화학적 성분에 영향 을 받을 수 있고, ${ }^{15,19,20,23}$ 특히 계면에서의 중합 정도는 재 료들의 결합에 심각한 영향을 미친다. ${ }^{16,19,22-24}$ 그러므로 복합 레진의 수리에 사용된 방법을 임시수복물 수리에 바로 적용하는 데는 주의가 필요하다. 실제로 선행 연구 에서 비스아크릴 임시수복 재료를 수리하는데 본딩제를 사용했을 때 수리강도의 증가에 유용한 효과를 얻지 못 한 경우도 있었다. ${ }^{714,15}$ 본딩제의 선택에 있어서 함께 사 용될 재료의 중합방식에 대한 고려가 중요한데, ${ }^{19,23}$ 임시 수복물 수리에 관한 연구에서 다양한 본딩제의 효과에 관한 연구는 많지 않았다.

본 연구에서는 중합방식과 화학적 조성이 다른 본딩제
들이 자가중합형 비스아크릴 임시수복 재료의 결합에 미 치는 영향을 알아보고자 하였다. 귀무가설은 본딩재의 화학적 특성이 자가중합형 비스아크릴 임시수복 재료의 수리강도에 영향을 미치지 않는다로 정하였으며 전단결 합 강도와 파절양상을 분석하여 수리강도에 미치는 영향 을 가늠 하였고 유의수준은 0.05 로 정하였다.

\section{연구 재료 및 방법}

임시수복물을 제작하는 과정에 재료의 추가가 필요 한 경우를 가정하여 연구방법을 설계하였으며 실험군들 을 Table 1 과 같이 설정하였다. 사용된 재료들에 관한 정 보는 Table 2에 정리 하였다. 시편 제작을 위해 $10 \mathrm{~mm} \times$ $5 \mathrm{~mm}$ (직경 $\times$ 높이)의 실리콘 몰드를 준비하였고 비스 아크릴 임시수복 재료(Luxatemp ${ }^{\circledR}$, DMG, Englewood, USA)를 주입하여 10 분간 중합이 완료되도록 기다린 후 제거하였다. 총 40 개의 시편이 제작되었으며 군별로 각 10 개의시편을 사용하였다. 시편을 직경 $30 \mathrm{~mm}$ 의 원통 형 테플론몰드 바닥 중앙에 위치시키고 자가중합레진 (Ortho-Jet ${ }^{\circledR}$, Lang Dental Manufacturing Co., Wheeling, USA)을 사용하여 포매하였다. 포매된 시편의 표면을 다 듬고 균일한 거칠기를 부여하기 위해 \#220-grit 의 사포 로 연마하였고, 에틸 알코올과 증류수로 세척하고 건조 하였다. 준비된 시편은 상온의 공기중에 보관하였다.

Table 1. Experiment design

\begin{tabular}{clc}
\hline Group code & \multicolumn{1}{c}{ Description } & $\mathrm{N}$ \\
\hline CO & Luxatemp + Luxatemp, no bonding material, control group & $\mathrm{n}=10$ \\
CF & Luxatemp + CIEARFIL (chemical cure bonding agent) + Luxatemp & $\mathrm{n}=10$ \\
SB & Luxatemp + Single bond 2 (light cure bonding agent) + Luxatemp & $\mathrm{n}=10$ \\
OS & Luxatemp + ONE-STEP (light cure bonding agent) + Luxatemp & $\mathrm{n}=10$ \\
\hline
\end{tabular}

CO, control; CF, CLEARFIL; SB, Single bond 2; OS, ONE-STEP.

Table 2. Materials used in this study

\begin{tabular}{|c|c|c|c|}
\hline Product & Manufacturer & Composition & Batch \\
\hline Luxatemp $^{\circledR}$ & DMG, Hamburg, Germany & Bis-acryl composite resin & 706439 \\
\hline Ortho-Jet ${ }^{\circledR}$ & Lang dental, Wheeling, USA & Acrylic resin & 602713AI/01AD \\
\hline CLEARFIL $^{\text {TM }}$ NEW BOND & Kuraray Medical Inc., Osaka, Japan & Chemical-cure bonding agent & 053830 \\
\hline Adper Single bond 2 & 3M ESPE, St. Paul, USA & Light-cure bonding agent & N457137 \\
\hline ONE-STEP ${ }^{\circledR}$ PLUS & Bisco, Schaumburg, USA & Light-cure bonding agent & 1200008878 \\
\hline Elipar ${ }^{\mathrm{TM}}$ FreeLight 2 & 3M ESPE, St. Paul, USA & LED Curing light & \\
\hline
\end{tabular}


각 군별로 시편 표면에 다음과 같이 본딩제를 각각 의 제조사 지시대로 처리하였다. 자가중합 개시제를 별 도로 제공하는 이중중합 방식의 본딩제(CLEARFIL ${ }^{\mathrm{TM}}$ NEW BOND, Kuraray Noritake Dental, Tokyo, Japan) 는 Bonding agent universal liquid와 Catalyst liquid를 1 : 1 비율로 혼합하고 마이크로 브러시로 도포 후 1 분간 약 한 압축공기로 건조하였다(Group $\mathrm{CF}$ ). 광중합형 본딩제 (Adper ${ }^{\mathrm{TM}}$ Single bond 2, 3M ESPE, St. Paul, USA)는 15 초간 동안 2회 마이크로 브러시로 도포하고 5 초간 약한 압축공기로 건조한 후 10 초 동안 광중합 하였다(Group $\mathrm{SB})$. 광중합형 본딩제 이지만 별도의 중합개시제 없이 자 가중합 레진과의 결합을 특성으로 하는 본딩제 $(\mathrm{ONE}-$ STEP $^{\circledR}$ PLUS, Bisco Inc., Schaumberg, USA)는 제조사 의 권장대로 본딩제를 충분히 흔든 후 사용하였으며 2회 도포 후 10 초간 약한 압축공기로 건조하였고 10 초간 광 중합 하였다(Group OS). 광중합은 Elipar ${ }^{\mathrm{TM}}$ FreeLight 2 LED Curing Light (3M ESPE)를 1,200 $\mathrm{mW} / \mathrm{cm}^{2}$ 으로 적용하여 시행하였다. 대조군으로는 본딩제를 처리하지 않은 시편을 사용하였다(Group CO).

본딩제 도포 후 직경 $4 \mathrm{~mm}$ 의 원형 구멍을 가진 $4 \mathrm{~mm}$ 두께의 테플론 몰드 $(20 \times 20 \mathrm{~mm}$; 가로 $\times$ 세로 $)$ 를 시편 에 고정시키고 비스아크릴 임시수복 재료를 구멍에 직접 주입 하였다. 중합이 되도록 5 분간 기다린 후 몰드를 제 거하여 시편을 완성하였다(Fig. 1).

완성된 시편은 상온의 공기 중에 24시간 보관한 후 만

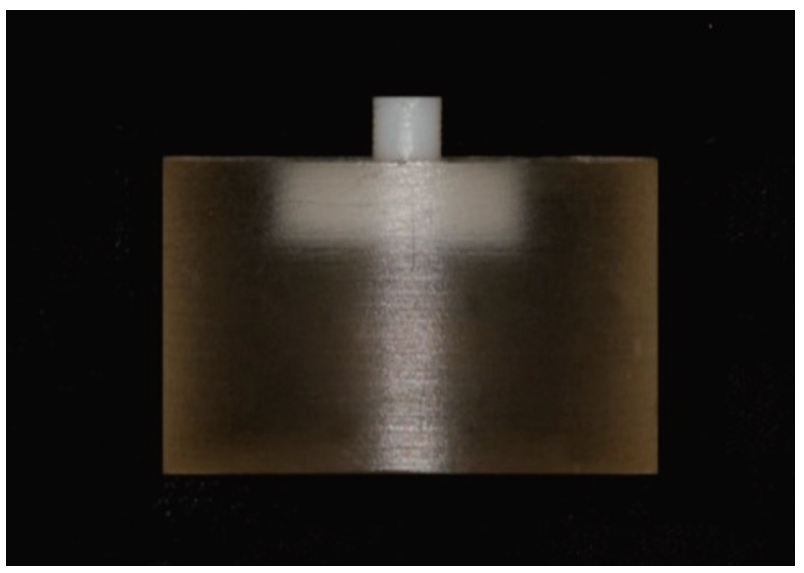

Fig. 1. Specimen before shear bond strength test. Bisacryl provisional material specimen was embedded in clear acrylic resin to be hold by special jig.
능시험기(Instron 3344, Instron Co., Norwood, USA)를 사용하여 분당 $0.5 \mathrm{~mm}$ 의 crosshead speed로 파절이 발 생하는 시점까지 압력을 가하여 전단결합강도를 측정하 였다(Fig. 2). 전단 결합강도는 파절 시 최대값(N)을 시편 의 표면적으로 나누어 megapascal (MPa)로 구하였다. 전 단결합강도 실험은 ISO/TS 11405 (Dental MaterialsTesting of adhesive to tooth structure)에 따랐으며, Fig. 2 와 같이 계면에 힘을 가하였다.

파절된 시편은 입체현미경(stereomicroscope, SZ601, Olympus, Tokyo, Japan)을 이용하여 10배율로 관찰 하 였고 비스아크릴 임시수복 재료 내부에서 파절이 발생한 경우를 응집 파절(cohesive failure), 본딩의 계면에서 발 생한 경우는 접착 파절(adhesive failure), 두 가지 재료를 모두 포함한 경우를 혼합 파절(mixed failure)로 분류하 였다.

평균 전단 결합강도 값을 계산한 후 통계분석 프로그 램(PASW for Windows, Ver. 18.0, SPSS Inc., Chicago, USA)으로 일원배치 분산분석과 Tukey 사후분석을 사용 하여 유의수준 0.05 로 검증하였다.

\section{결과}

각 실험군의 평균 전단강도 값과 파절양상을 Table 3 에 정리하였다. 얻어진 전단결합강도를 통계적으로 분 석한 결과 각 군간에 유의한 차이가 있었고(Table 4) 사

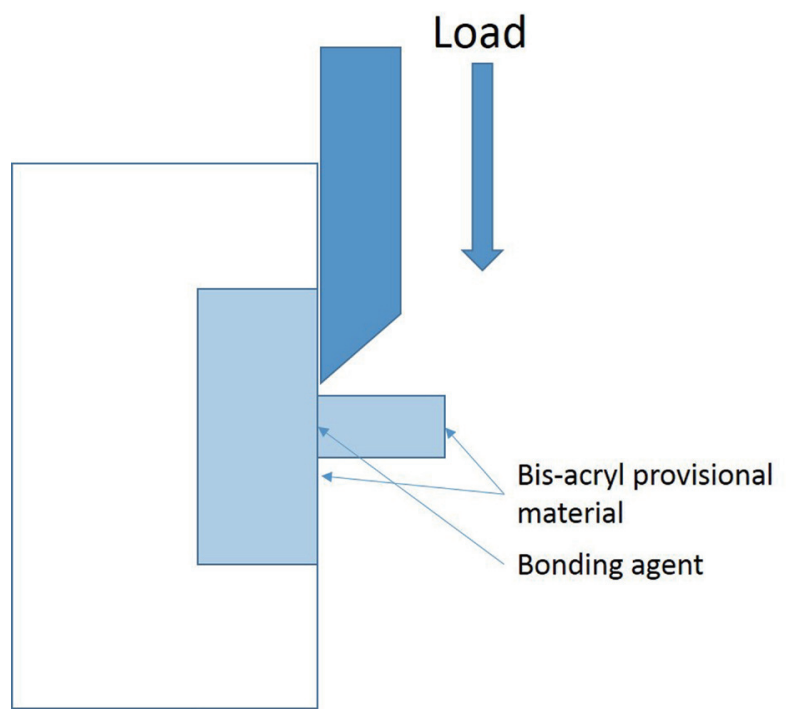

Fig. 2. Schematic drawing of shear bond strength test. Load was applied at bonding interface. 
Table 3. Mean and standard deviation (SD) of shear bond strength (unit: Mpa) and failure mode analysis of all specimens (unit: \%)

\begin{tabular}{ccccc}
\hline Groups & Mean \pm SD & Cohesive fracture & Mixed fracture & Adhesive fracture \\
\hline CO & $12.56 \pm 3.30$ & - & 100 & - \\
CF & $27.36 \pm 4.30$ & 100 & - & - \\
SB & $13.29 \pm 2.56$ & - & 80 & 20 \\
OS & $19.20 \pm 6.92$ & - & 80 & 20 \\
\hline
\end{tabular}

CO, control; CF, CLEARFIL; SB, Single bond 2; OS, ONE-STEP.

Table 4. Result of One-way ANOVA test on shear bond strength

\begin{tabular}{cccccc}
\hline & Sum of squares & df & Mean square & F & Sig. \\
\hline Intergroup & 222573.161 & 3 & 74191.054 & 20.475 & \\
Intragroup & 130446.077 & 36 & 3623.502 & & \\
Sum & 353019.238 & 39 & & & \\
\hline
\end{tabular}

df, degree of freedom; Sig., significance.

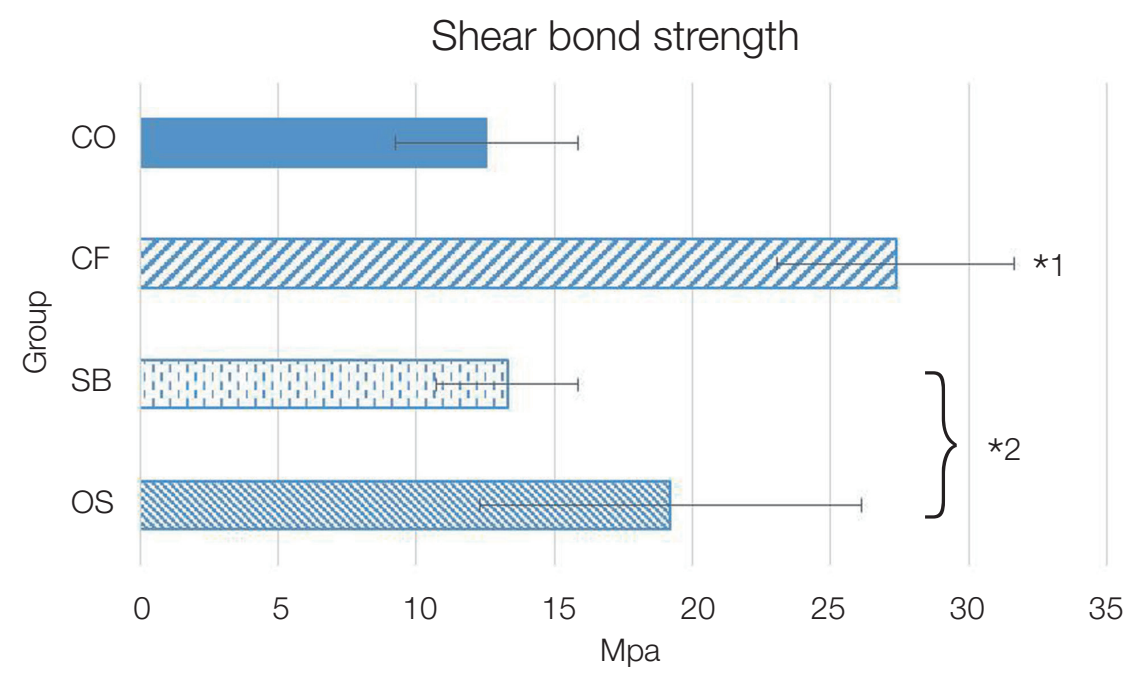

Fig. 3. Shear bond strengths of groups are compared and statistically analysed. According to the Turkey post hoc test results, $* 1$ denotes significantly different from the others at the significance level of 0.05 . $* 2$ denotes significant difference between groups at the significance level of 0.05. CO, control; CF, CLEARFIL; SB, Single bond 2; OS, ONE-STEP.

후검정 결과를 그래프에 통계적 유의성으로 표시하였 다(Fig. 3). 가장 높은 전단결합 강도는 화학중합형 본 딩제를 사용한 군(Group CF)에서 나타났으며(27.36 \pm $4.30 \mathrm{MPa})$ 모든 시편에서 비스아크릴 임시수복 재료에 서 파절이 일어나는 응집 파절을 보였다 $(100 \%)$. 이는 아 무런 본딩처리를 하지 않은 대조군(Group CO, $12.56 \pm$ $3.30 \mathrm{MPa})$ 에 비해 두 배 이상 높은 값을 보인 것으로 다 른 실험군들과도 통계적으로 유의한 차이를 보였다 $(P<$
0.05). 실험군중 가장 낮은 값은 광중합형 본딩제를 사용 한 군(Group SB)에서 기록되었으며(13.29 $\pm 2.56 \mathrm{MPa})$ 이는 대조군과 거의 유사한 값을 보였다. 파절양상은 Group CF를 제외하고 대부분 혼합 파절을 보였다. 동일 한 광중합 방식 이지만 자가중합 레진과의 호환성을 높 였다는 본딩제를 사용한 경우(Group OS) 전단결합강도 에서 우수한 값을 보였으며 Group SB와 Group OS간에 통계적으로 유의한 차이로 나타났다 $(P=0.043)$. 


\section{고찰}

비스아크릴 레진이 주성분인 임시수복물 재료의 수리 나 첨가에 있어서 본딩제의 화학적 성질이 미치는 영향 을 평가하기 위해 3종의 각기 다른 특성을 가지는 본딩제 를 도포하여 제작한 시편과 도포하지 않은 시편의 수리 전단결합 강도를 비교하였다. 임시수복물은 치아를 보 호하기 위해 좋은 변연 적합을 가져야 하며 이는 재이장 과정을 통해 향상될 수 있다. ${ }^{5}$ 비록 비스아크릴 임시수복 재료가 다른 임시수복 재료에 비해 우수한 변연적합을 보이기는 하지만 이는 재이장 과정을 하지 않은 상태에 서의 비교가 대부분의 연구결과 이었다. ${ }^{4,910}$ Polymethyl methacrylate (PMMA) 재료의 경우 높은 중합 수축으 로 변연적합의 불량이 발생하고 또 중합 시 발생하는 열 로 인한 치수자극을 피하기 위해 구강 내에서 직접적으 로 제작할 때 완전히 중합이 일어나기 전에 제거해야 하 기 때문에 이로 인해 변연 적합에 문제가 발생한다. ${ }^{3,11}$ 그 러나 PMMA는 첨가되는 재료와 본 재료간의 우수한 결 합으로 수리와 재이장이 가능하여 이러한 단점을 극복 할 수 있으며 $3,5,7,13$ 간접법으로 제작 후 구강 내에서 재이 장하고 필요한 부위를 자유로이 삭제, 첨가하는 술식상 의 편의성을 가지고 있다. ${ }^{3}$ 이런 점에서 비스아크릴 임시 수복 재료는 사용상의 편의성이나 교합, 물리적 특성의 우수함 ${ }^{3,410}$ 에도 불구하고 그 사용에 한계를 가질 수 밖에 없으며 수리나 첨가에 있어 신뢰할 수 있는 방법을 찾아 내는 것은 중요한 문제라고 할 수 있다.

복합 레진의 수리에 관한 연구들에서 기존 재료 표면 의 화학적 성질이 결합에 미치는 영향은 시간이 경과하 면서 점차 감소하며 ${ }^{24}$ 일정기간 사용한 레진의 수리에 있 어서 레진 표면의 물리적 처리가 수리 결합강도에 더 중 요한 영향을 미친다. ${ }^{17,26}$ 그러나 표면처리 후 사용하는 본딩제의 화학적 특성에 따라 새로 첨가되는 재료의 중 합반응과 결합력에 영향이 있을 수 있음이 알려져 있 다. ${ }^{16,17,19,20,23,24}$

비스아크릴 임시수복물의 수리에 관한 연구에 있어서 도 다양한 표면처리와 본딩제의 사용 효과에 대한 비교 가 있었다. ${ }^{7,13,14,15}$ Lee와 Lee ${ }^{15}$ 는 연구에서 본딩제의 사용 방법에 따라 결합 강도에 영향이 있을 수 있음을 보고하 였고, Dall'Oca 등 ${ }^{24}$ 과 Tay 등의 연구에 의하면 중합이 된 본딩제 이더라도 산소와 접촉된 표면의 미중합 층의 화 학적 성분이 새로 첨가되는 레진의 중합과 결합력에 영 향을 줄 수 있음을 보였다. 본 연구에서는 이러한 연구에
근거하여 서로 다른 특성을 가지는 본딩제들을 사용하였 을 때 비스아크릴 임시수복 재료간의 결합강도에 미치는 연구를 확인하고자 하였으며, 결과에서 임시수복 재료와 같은 화학중합 방식에서 가장 높은 결합강도를 보였고 광중합 전용으로 개발된 본딩제에서 가장 낮은 결합강도 를 보여 본딩제의 종류가 결합강도에 영향을 주는 것을 확인 할 수 있었다. 또한 Table 3 의 파절 양상에서 보듯이 높은 결합 강도를 보인 화학중합 본딩제 군에서는 응집 파절 양상을 보여 재료간의 결합이 매우 강했음을 보여 주었다.

최근의 본딩제들은 시술의 간편화와 다양한 표면에의 접착을 위하여 많은 작용기를 포함하며 self-etching을 위 해 낮은 산도를 가지는 특징이 있다. ${ }^{22,23}$ Sanares 등 ${ }^{20}$ 과 Franco 등 ${ }^{23}$ 은 낮은 산도가 화학중합형 레진의 중합에 영향을 미칠 수 있다고 하였다. 이는 계면의 표면에서 산 과 접촉한 중합 개시제가 변성되어 결합면에서 중합 정 도가 떨어지는 층을 형성하기 때문이라고 하였다. ${ }^{19,20,23}$ 새로 개발된 본딩제의 경우 이러한 문제점들을 어느 정 도 극복 하여 함께 사용되는 레진의 종류에 무관하게 재 료의 중합에 영향을 주지 않음을 강조하고 있으며, 본 실 험에서도 광중합 방식의 본딩제 이지만 화학중합 레진의 결합에 영향을 주지 않는다고 하는 제품을 포함시켜 보 았다. 실험결과 화학중합 방식 본딩제에 비해서는 낮은 값을 보였으나 광중합전용 본딩제에 비해서는 유의하게 높은 전단결합강도를 보였다. 따라서 비스아크릴 임시수 복 재료를 사용하여 임시수복물을 만들 때 동일한 재료 를 추가하는 수정이 필요한 경우 본딩제의 선택을 적절 하게 할 경우 본딩제를 사용하지 않는 경우보다 우수한 수리강도를 얻을 수 있을 것으로 생각되었다.

본 연구의 한계로는 우선 본 실험에서는 임시수복물의 수리강도를 비교하기 위해 전단결합 강도 측정을 사용하 였으나 다양한 응력환경하에 놓아는 임시수복물의 수리 강도를 전단결합 강도만으로 비교하기에는 한계가 있고 좀 더 다양한 파절시험이 함께 진행되는 것이 필요하다 는 것을 지적할 수 있겠다. 또한 비스아크릴 레진을 주성 분으로 하는 다양한 임시수복 재료와 좀 더 다양한 본딩 제들이 포함되지 못하였음을 지적할 수 있겠다. 따라서 앞으로 이러한 다양한 재료를 포함한 연구를 통해 재료 별로 가장 적절한 본딩제 조합을 찾아내는 것이 필요할 것으로 사료된다. 또한 본딩제로 처리된 결합표면의 화 학적 상태에 대한 좀 더 정밀한 연구가 필요할 것으로 생 각된다. 


\section{결론}

비스아크릴 임시수복재료의 수리 시 본딩제의 화학적 특성이 수리된 시편의 수리강도에 미치는 영향을 확인하 고자 실험을 시행하였고 다음과 같은 결론을 얻었다.

1. 본딩제의 종류에따라 비스아크릴 임시수복 재료의 전단결합 강도는 영향을 받았다.

2. 사용된 본딩제 중 화학중합형 본딩제의 사용시 가장 높은 전단결합 강도를 보였으며 이는 통계적으로 유의한 차이를 보였다.

3. 광중합형 본딩의 경우에서도 제품에 따라 유의하게 차이 나는 결합강도를 보였다.

4. 이상의 결과를 토대로 비스아크릴 임시수복 재료에 본딩제를 사용할 경우 사용하는 재료와의 호환성에 대한 신중한 고려가 필요함을 알 수 있었다.

\section{Acknowledgements}

이 연구는 2015년도 단국대학교 대학연구비의 지원으 로 연구되었음(과제번호: R-0001-28830).

\section{ORCID}

Jonghyuk Lee http://orcid.org/0000-0003-1976-4089

\section{References}

1. Federick DR. The provisional fixed partial denture. J Prosthet Dent 1975;34:520-6.

2. Vahidi F. The provisional restoration. Dent Clin North Am 1987;31:363-81.

3. Burns DR, Beck DA, Nelson SK. A review of selected dental literature on contemporary provisional fixed prosthodontic treatment: report of the Committee on Research in Fixed Prosthodontics of the Academy of Fixed Prosthodontics. J Prosthet Dent 2003;90:474-97.

4. Wang RL, Moore BK, Goodacre CJ, Swartz ML, Andres CJ. A comparison of resins for fabricating provisional fixed restorations. Int J Prosthodont 1989;2:173-84.

5. Zwetchkenbaum S, Weiner S, Dastane A, Vaidyanathan TK. Effects of relining on long-term marginal stability of provisional crowns. J Prosthet Dent 1995;73:525-9.

6. Bohnenkamp DM, Garcia LT. Repair of bis-acryl provisional restorations using flowable composite resin. J Prosthet Dent 2004;92:500-2.

7. Chen HL, Lai YL, Chou IC, Hu CJ, Lee SY. Shear bond strength of provisional restoration materials repaired with light-cured resins. Oper Dent 2008; 33:508-15.

8. Hammond BD, Cooper JR 3rd, Lazarchik DA. Predictable repair of provisional restorations. J Esthet Restor Dent 2009;21:19-24.

9. Tjan AH, Castelnuovo J, Shiotsu G. Marginal fidelity of crowns fabricated from six proprietary provisional materials. J Prosthet Dent 1997;77:482-5.

10. Young HM, Smith CT, Morton D. Comparative in vitro evaluation of two provisional restorative materials. J Prosthet Dent 2001;85:129-32.

11. Driscoll CF, Woolsey G, Ferguson WM. Comparison of exothermic release during polymerization of four materials used to fabricate interim restorations. J Prosthet Dent 1991;65:504-6.

12. Koumjian JH, Nimmo A. Evaluation of fracture resistance of resins used for provisional restorations. J Prosthet Dent 1990;64:654-7.

13. Balkenhol M, Meyer M, Michel K, Ferger P, Wöstmann B. Effect of surface condition and storage time on the repairability of temporary crown and fixed partial denture materials. J Dent 2008;36:86172.

14. Hagge MS, Lindemuth JS, Jones AG. Shear bond strength of bis-acryl composite provisional material repaired with flowable composite. J Esthet Restor Dent 2002;14:47-52.

15. Lee J, Lee S. Evaluation of add-on methods for bis-acryl composite resin interim restorations. J Prosthet Dent 2015;114:594-601.

16. Eliades GC, Caputo AA. The strength of layering technique in visible light-cured composites. J Prosthet Dent 1989;61:31-8.

17. Brosh T, Pilo R, Bichacho N, Blutstein R. Effect of combinations of surface treatments and bonding agents on the bond strength of repaired composites. J Prosthet Dent 1997;77:122-6.

18. Shahdad SA, Kennedy JG. Bond strength of re- 
paired anterior composite resins: an in vitro study. J Dent 1998;26:685-94.

19. Tay FR, King NM, Suh BI, Pashley DH. Effect of delayed activation of light-cured resin composites on bonding of all-in-one adhesives. J Adhes Dent 2001;3:207-25.

20. Sanares AM, Itthagarun A, King NM, Tay FR, Pashley DH. Adverse surface interactions between one-bottle light-cured adhesives and chemicalcured composites. Dent Mater 2001;17:542-56.

21. Truffier-Boutry D, Place E, Devaux J, Leloup G. Interfacial layer characterization in dental composite. J Oral Rehabil 2003;30:74-7.

22. Suh BI. Oxygen-inhibited layer in adhesion dentistry. J Esthet Restor Dent 2004;16:316-23.

23. Franco EB, Lopes LG, D’Alpino PH, Pereira JC. Influence of $\mathrm{pH}$ of different adhesive systems on the polymerization of a chemically cured composite resin. Braz Dent J 2005;16:107-11.

24. Dall'Oca S, Papacchini F, Goracci C, Cury AH, Suh BI, Tay FR, Polimeni A, Ferrari M. Effect of oxygen inhibition on composite repair strength over time. J Biomed Mater Res B Appl Biomater 2007; 81:493-8.

25. Rinastiti M, Ozcan M, Siswomihardjo W, Busscher HJ. Immediate repair bond strengths of microhybrid, nanohybrid and nanofilled composites after different surface treatments. J Dent 2010;38:29-38.

26. Jafarzadeh Kashi TS, Erfan M, Rakhshan V, Aghabaigi N, Tabatabaei FS. An in vitro assessment of the effects of three surface treatments on repair bond strength of aged composites. Oper Dent 2011;36:608-17. 


\section{임시수복 재료와 본딩제의 화학적 호환성이 전단결합강도에 미치는 영향}

\section{이종혁*}

단국대학교 치과대학 치과보철학교실

목적: 중합방식과 화학적 조성이 다른 본딩제들이 자가중합형 비스아크릴 임시수복 재료의 결합에 미치는 영향을 알아 보고자 하였다.

연구 재료 및 방법: 원반 형태의 비스아크릴 임시수복 재료 시편 40 개를 준비한 후 본딩제의 중합특성에 따라 대조군을 포함 4개의 군으로 나누었다. 본딩제 도포 후 직경 $4 \mathrm{~mm}$ 의 원형 구멍을 가진 $4 \mathrm{~mm}$ 두께의 테플론 몰드를 이용하여 동 일한 비스아크릴 임시수복 재료을 첨상하였다. 전단결합강도시험을 시행하였으며 파절면을 현미경으로 관찰하였다. 일 원배치 분산분석과 Tukey 사후분석을 사용하여 유의수준 0.05 로 검증하였다.

결과 : 화학중합형 본딩제를 사용한 군에서 통계적으로 유의한 가장 높은 전단결합강도를 보였으며(27.36 $\pm 4.30 \mathrm{MPa}, P$ $<0.05)$ 모든 시편에서 비스아크릴 임시수복 재료 내에서 파절이 일어나는 응집성 파절 양상을 보였다 $(100 \%)$. 실험군중 가장 낮은 값은 광중합형 본딩제를 사용한 군에서 기록되었으며(13.29 $\pm 2.56 \mathrm{MPa})$ 이는 대조군과 거의 유사한 값을 보 였다. 동일한 광중합 방식 이지만 화학중합 레진과의 호환성을 높인 본딩제를 사용한 군에서는 광중합형 본딩제를 사용 한 군에 비해 통계적으로 유의하게 높은 값을 보였다 $(P=0.043)$.

결론: 본딩제의 종류가 수리된 비스아크릴 임시수복 재료의 전단결합 강도에 영향을 주며, 비스아크릴 임시수복 재료의 수리 시 적절한 본딩제 선택이 중요하다.

주요어: 비스아크릴 임시수복 재료; 임시 수복물; 전단결합강도; 본딩제 